\title{
Bayesian VAR Modeling and Forecasting of the Dynamic Interrelationship between Economic Growth and Revenue from Oil and Non-Oil Sectors in Nigeria ${ }^{+}$
}

\author{
Monday Osagie Adenomon \\ Department of Statistics, Nasarawa State University, Keffi, Nasarawa State \\ adenomonmo@nsuk.edu.ng;+23407036990145
}

\begin{abstract}
The present reality about the Nigerian economy calls for investment and development in the non-oil sector. This becomes necessary as a result of fall in the oil price in the global market. This paper examined the Bayesian Vector Autoregression (BVAR) modeling and forecasting of the dynamic interrelationship between Economic growth and revenue from the oil and non-oil sectors in Nigeria. To achieve this, annual data on Gross Domestic Product (GDP), revenue from oil and non-oil sectors were collected from Central Bank of Nigeria (CBN) bulletin, the sample from 1981 to 2008 was used for analysis, while sample from 2009 to 2014 was used for model validation. Six (6) versions of Sims-Zha BVAR models were compared for out-of-sample forecast, the result revealed the superiority of the BVAR6 model over the other BVAR models. Lastly, evidence from the decomposition forecast errors revealed that revenue of oil sector contributed $7.69 \%$ to GDP while revenue from non-oil sector contributed $0.12 \%$ to GDP in Nigeria. This paper therefore recommended that the present government should encourage investment that is geared toward development in the non-oil sector, of which it has the capacity to improve the Economic growth of the Nigerian economy.
\end{abstract}

Keywords: Bayesian Vector Autoregression (BVAR), Modeling, Forecasting, Gross Domestic Product (GDP), Economic Growth, Revenue, Oil sector, Non-oil Sector

\section{Introduction}

Revenue is defined as all amounts of money received by a government from external sources for example those originating from "outside the government" net of refunds and other correcting transaction, proceeds from issuance debt, sale of investments, agency or private trust transactions, and intra-governmental transfers (Ahmed, 2010; Okwori \& Sule, 2016). For instance in Nigeria, provision of economic infrastructures, social services, debt services, providing the Army, the Police, the court system and any other operation of the government, are provided by the Nigerian government through oil revenue, non-oil revenue and federal government independent revenue (Omachi, 2011). Unfortunately, the Nigerian economy has suffers decline in revenue during this period of recession, leading to high inflation rate and leading to shortfalls in government capital and recurrent expenditures. 
The following are related literature review: Ude and Agodi (2012) used cointegration and error correction model to investigate the impact of non-oil revenue on economic growth in Nigeria. They used annual data from 1980 to 2013 and the study revealed that agricultural revenue, manufacturing revenue and interest rate have significant impact on economic growth in Nigeria. Offia (2012) examined the impact of non-oil exports on economic growth in Nigeria from 1986-2010. Results from multiple regression revealed that non-oil export is statistically significant to Nigeria economic growth. In a similar work by Abogan et al (2014) investigated the impact of non-oil export on economic growth in Nigeria between 1980 and 2010. Evidence from ordinary least squares method involving error correction mechanism revealed that the impact of non-oil export on economic growth was moderate. Akwe (2014) investigated the impact of non-oil tax revenue on economic growth in Nigeria. Results from the empirical study revealed a statistical significance of economic growth effects of non-oil tax revenue. Oziengbe (2015) investigated the effects of important penetration and FDI inflows on the performance of Nigera's non-oil exports in the period from 1981-2012 using the methodology of ARDL (Bounds test) approach to cointegration and error correction analysis. The study indicated that import penetration impacted positively on the performance of Nigeria's non-oil export in the short run, though its long run impact was negative. The short run and long run impact of FDI on non-oil export performance were not statistically significant. Furthermore, the currency depreciation positively impact the performance of Nigeria's non-oil export in the long run, but its short run impact was not significant. Okwori \& Sule (2016) fitted a long run relationship between GDP and Oil revenue, non-oil revenue, domestic debt and external debt in Nigeria. Evidence from their study revealed that oil revenue, non-oil revenue and external debt are positively related to GDP while domestic debt was negatively related to GDP. Okezie and Azubike (2016) evaluated the contribution of non-oil revenue to government revenue and economic growth in Nigeria from 1980 to 2014. Results from ordinary least squares regression revealed a positive and significant contribution of non-oil revenue to economic growth and positive insignificant contribution to government revenue.

This study therefore examined the contribution of oil and non-oil revenues to Gross Domestic Product (GDP) growth rate in Nigeria using six (6) versions of Sims-Zha Bayesian Vector Autoregressive (BVAR) models for out-of-sample forecast comparison.

\section{Model Specification and Description}

\section{Bayesian Vector Autoregression with Sims-Zha Prior}

One of the advantages of Bayesian VAR over the Classical VAR, is its suitability in small sample time series. In time series literature, many versions of BVAR are available. These include Litterman prior, Jeffery prior and Sims-Zha prior etc. In recent times, the BVAR model of Sims and Zha (1998) has gained popularity both in economic time series and political analysis. One major advantage of the Sims-Zha BVAR is that it allows for a more general specification and can produce a tractable multivariate normal posterior distribution. Again, the 
Sims-Zha BVAR estimates the parameters for the full system in a multivariate regression (Brandt and Freeman, 2006).

Given the reduced form model

$y_{t}=c+y_{t-1} B_{1}+\ldots+y_{t-p} B_{p}+u_{t}$

where $c=d A_{0}^{-1}, B_{l}=-A_{l} A_{0}^{-1}, l=1,2, \ldots p, u_{t}=\varepsilon_{t} A_{0}^{-1}$ and $\Sigma=A_{0}^{-1} A_{0}^{-1}$

The matrix representation of the reduced form is given as

$$
\underset{T \times m}{Y}=\underset{T \times(m p+1)}{X} \underset{(m p+1) \times m}{\beta}+\underset{T \times m}{U}, U \sim \operatorname{MVN}(0, \Sigma)
$$

We can then construct a reduced form Bayesian SUR with the Sims-Zha prior as follows. The prior means for the reduced form coefficients are that $B_{1}=I$ and $B_{2}, \ldots B_{p}=0$. We assume that the prior has a conditional structure that is multivariate Normal-inverse Wishart distribution for the parameters in the model. To estimate the coefficients for the system of the reduced form model with the following estimators

$\hat{\beta}=\left(\Psi^{-1}+X^{\prime} X\right)^{-1}\left(\Psi^{-1} \bar{\beta}+X^{\prime} Y\right)$

$\hat{\Sigma}=T^{-1}\left(Y^{\prime} Y-\hat{\beta}^{\prime}\left(X^{\prime} X+\Psi^{-1}\right) \hat{\beta}+\bar{\beta}^{\prime} \Psi^{-1} \bar{\beta}+\bar{S}\right)$

where the Normal - inverse Wishart prior for the coefficients is

$\beta / \Sigma \sim N(\bar{\beta}, \Psi)$ and $\Sigma \sim I W(\bar{S}, v)$

This representation translates the prior proposed by Sims and Zha form from the structural model to the reduced form (Brandt and Freeman, (2006, 2009), and Sims and Zha, (1998, 1999).

The summary of the Sims-Zha prior is given in Table 1.0.

\section{Table 1.0: Hyperparameters of Sims-Zha reference prior}

\begin{tabular}{|lll|}
\hline Parameter & Range & Interpretation \\
\hline$\lambda_{0}$ & {$[0,1]$} & Overall scale of the error covariance matrix \\
$\lambda_{1}$ & $>0$ & Standard deviation around $A_{1}$ (persistence) \\
$\lambda_{2}$ & $=1$ & Weight of own lag versus other lags \\
$\lambda_{3}$ & $>0$ & Lag decay \\
$\lambda_{4}$ & $\geq 0$ & Scale of standard deviation of intercept \\
$\lambda_{5}$ & $\geq 0$ & Scale of standard deviation of exogenous variable coefficients \\
$\mu_{5}$ & $\geq 0$ & Sum of coefficients/Cointegration (long-term trends) \\
$\mu_{6}$ & $\geq 0$ & Initial observations/dummy observation (impacts of initial conditions ) \\
$\mathrm{v}$ & $>0$ & Prior degrees of freedom \\
\hline
\end{tabular}

Source: Brandt and Freeman, (2006)

This study considered six (6) versions of Sims-Zha Bayesian VAR model given below 


$$
\begin{aligned}
& \operatorname{BVAR} 1=\left(\lambda_{0}=0.6, \lambda_{1}=0.1, \lambda_{3}=1, \lambda_{4}=0.1, \lambda_{5}=0.07, \mu_{5}=\mu_{6}=5\right) \\
& \operatorname{BVAR} 2=\left(\lambda_{0}=0.8, \lambda_{1}=0.1, \lambda_{3}=1, \lambda_{4}=0.1, \lambda_{5}=0.07, \mu_{5}=\mu_{6}=5\right) \\
& \operatorname{BVAR} 3=\left(\lambda_{0}=0.6, \lambda_{1}=0.15, \lambda_{3}=1, \lambda_{4}=0.15, \lambda_{5}=0.07, \mu_{5}=\mu_{6}=2\right) \\
& \operatorname{BVAR} 4=\left(\lambda_{0}=0.8, \lambda_{1}=0.15, \lambda_{3}=1, \lambda_{4}=0.15, \lambda_{5}=0.07, \mu_{5}=\mu_{6}=2\right) \\
& \operatorname{BVAR5}=\left(\lambda_{0}=0.9, \lambda_{1}=0.1, \lambda_{3}=1, \lambda_{4}=0.1, \lambda_{5}=0.07, \mu_{5}=\mu_{6}=2\right) \\
& \operatorname{BVAR6}=\left(\lambda_{0}=0.9, \lambda_{1}=0.15, \lambda_{3}=1, \lambda_{4}=0.15, \lambda_{5}=0.07, \mu_{5}=\mu_{6}=5\right)
\end{aligned}
$$

where $n \mu$ is prior degrees of freedom given as $m+1$ where $m$ is the number of variables in the multiple time series data. In this work $n \mu$ is 4 (that is three (3) time series variables plus 1(one)). The following are the criteria for Forecast assessments used:

1. Mean Absolute Error (MAE) has a formular $M A E_{j}=\frac{\sum_{i=1}^{n}\left|e_{i}\right|}{n}$. This criterion measures deviation from the series in absolute terms, and measures how much the forecast is biased. This measure is one of the most common ones used for analyzing the quality of different forecasts.

2. The Root Mean Square Error (RMSE) is given as $R M S E_{j}=\sqrt{\frac{\sum_{i}^{n}\left(\mathrm{y}_{i}-\mathrm{y}^{f}\right)^{2}}{n}}$ where $\mathrm{y}_{\mathrm{i}}$ is the time series data and $\mathrm{y}^{\mathrm{f}}$ is the forecast value of $\mathrm{y}$ (Caraiani, 2010).

For the two measures above, the smaller the value, the better the fit of the model (Cooray, 2008)

\section{Materials and Methods}

The data used in this paper was sourced from CBN 2014 Statistical Bulletin. The data on annual GDP, Oil revenue and non-oil revenue in Nigeria spanned from 1981 to 2014. The unit of measurement for GDP, Oil revenue and non-Oil revenue are all in Billion naira ( $)$. The sample from 1981 to 2008 was used for analysis, while sample from 2009 to 2014 was used for model validation.

\section{Results and Discussion}

To carry out a BVAR analysis, it is required to obtain the optimal lag for the model. Result from the VAR lag specification revealed lag 6 as the optimal (see table 2 below for detail) Table 2: VAR lag Specification

\begin{tabular}{|lrrrr|}
\hline \multicolumn{2}{|l}{ \$ldets } & & & \\
& Lags & Log-Det & Chi^2 & p-value \\
{$[1]$,} & 6 & 8.090737 & 44.163130 & $1.317016 e-06$ \\
{$[2]$,} & 5 & 22.811780 & 21.768731 & $9.641553 e-03$ \\
{$[3]$,} & 4 & 26.439902 & 38.292377 & $1.544683 e-05$ \\
{$[4]$,} & 3 & 30.694610 & 39.015096 & $1.144858 e-05$ \\
{$[5]$,} & 2 & 33.945868 & 5.607955 & $7.784235 e-01$ \\
{$[6]$,} & 1 & 34.319732 & 0.000000 & $0.000000 e+00$ \\
\$results & & & \\
\hline
\end{tabular}




\begin{tabular}{|lrrrr|}
\hline & Lags & AIC & BIC & HQ \\
{$[1]$,} & 1 & 35.41064 & 36.00576 & 35.55083 \\
{$[2]$,} & 2 & 35.85496 & 36.89641 & 36.10029 \\
{$[3]$,} & 3 & 33.42188 & 34.90967 & 33.77236 \\
{$[4]$,} & 4 & 29.98536 & 31.91948 & 30.44098 \\
{$[5]$,} & 5 & 27.17542 & 29.55587 & 27.73618 \\
{$[6]$,} & 6 & 13.27255 & 16.09935 & 13.93846 \\
attr (, "class") & & \\
{$[1]$} & & & \\
\end{tabular}

The analysis of the variables (GDP, Oil revenue and non-Oil revenue) using BVAR in R, and the forecast were compared with the actual values of the variable using the forecast assessment criteria and the result is presented in table 3 below.

Table 3: Performance Ratings of the six (6) version of Sims-Zha Bayesian VAR

\begin{tabular}{|l|l|l|}
\hline Models & \multicolumn{1}{|c|}{ RMSE } & \multicolumn{1}{c|}{ MAE } \\
\hline BVAR1 & 12532.12 & 8453.85 \\
\hline BVAR2 & 12294.701 & 8360.998 \\
\hline BVAR3 & 12206.281 & 8329.391 \\
\hline BVAR4 & 12020.970 & 8270.493 \\
\hline BVAR5 & 12206.281 & 8329.391 \\
\hline BVAR6 & $\mathbf{1 1 9 2 4 . 6 0 5}$ & $\mathbf{8 2 3 7 . 3 5 3}$ \\
\hline
\end{tabular}

From the table 3 above the minimum RMSE and MAE is associated with BVAR6. Hence BVAR6 is the best model among others. Details of BVAR6 are presented at the appendix.

Table 4A: Actual Series from 2009 to 2014

\begin{tabular}{|r|r|r|r|}
\hline \multicolumn{4}{|c|}{ Actual Series } \\
\hline Year & GDP & Oil Revenue & Non-Oil Revenue \\
\hline 2009 & 24794.24 & 3191.94 & 1652.65 \\
2010 & 54612.26 & 5396.09 & 1907.58 \\
2011 & 62980.4 & 8878.97 & 2237.88 \\
2012 & 71713.94 & 8025.97 & 2628.78 \\
2013 & 80092.56 & 6809.23 & 2950.56 \\
2014 & 89043.62 & 6793.72 & 3275.12 \\
\hline
\end{tabular}

Table 4B: BVAR6 Forecast Series from 2009 to 2014

\begin{tabular}{|cccl|}
\hline \multicolumn{4}{|c|}{ Forecast from BVAR6 Model } \\
\hline Year & GDP & Oil Revenue & Non-Oil Revenue \\
\hline 2009 & 29037.08 & 8001.757 & 1612.811 \\
2010 & 34639.98 & 9464.051 & 1932.150 \\
2011 & 41239.29 & 11119.764 & 2293.535 \\
\hline
\end{tabular}




\begin{tabular}{|llll|}
\hline 2012 & 49022.26 & 13167.680 & 2724.771 \\
2013 & 58297.99 & 15700.070 & 3239.744 \\
2014 & 69353.94 & 18699.247 & 3853.369 \\
\hline
\end{tabular}

Model validation used the actual series in Table 4A to compare the forecast from BVAR6 in Table 4B. The Impulse response function for the model is presented at the appendix.

Table 5: Decomposition of Forecast Errors for a Shock to GDP

$\begin{array}{rrrrr} & \text { Std. Error } & \text { gdp } & \text { oilrev nonoilrev } \\ {[1,]} & 768.5614 & 84.28936 & 15.249626 & 0.4610175 \\ {[2,]} & 1143.1991 & 88.12734 & 11.659314 & 0.2133470 \\ {[3,]} & 1474.9375 & 90.73917 & 9.121355 & 0.1394709 \\ {[4,]} & 1819.1347 & 92.18394 & 7.693131 & 0.1229263\end{array}$

In table 5 above on decomposition of forecast errors for a shock to GDP at step 4 revealed that Oil revenue contributed $7.69 \%$ to GDP while Non-Oil revenue contributed only $0.12 \%$ to GDP in Nigeria. This result revealed that oil revenue still dominates the non-oil revenue in terms of their contribution to GDP in Nigeria which agrees with Omachi (2011) and contradict the findings of Okezie and Azubike (2016). The implication of this finding show some level of overdependence on oil sector and a level of neglect on the non-oil sector.

\section{Conclusion}

This paper examined the Bayesian Vector Autoregression (BVAR) modeling and forecasting of the dynamic interrelationship between Economic growth and revenue from the oil and non-oil sectors in Nigeria. To achieve this, annual data on Gross Domestic Product (GDP), revenue from oil and non-oil sectors were collected from Central Bank of Nigeria (CBN) bulletin from 1981 to 2014. The sample from 1981 to 2008 was used for analysis, while sample from 2009 to 2014 was used for model validation. Six (6) versions of Sims-Zha BVAR models were compared for out-of-sample forecast, the result revealed the superiority of the BVAR6 model over the other BVAR models. Lastly, evidence from the decomposition forecast errors revealed that revenue of oil sector contributed $7.69 \%$ to GDP while revenue from non-oil sector contributed $0.12 \%$ to GDP in Nigeria. This paper therefore recommended that the present government should encourage investment that is geared toward development in the non-oil sector (for instance agriculture, mining etc), of which it has the capacity to improve the Economic growth of the Nigerian economy. 


\section{References}

Abogan, O. P; Akinola, E. B. \& Baruwa, O. I.(2014): Non-Oil Export and Economic Growth in Nigeria (1980-2011). JREIF, 3(1):1-11.

Ahmed, Q. M. (2010): Determinants of Tax Buoyancy: Empirical Evidence from Developing Countries. European Journal of Social Sciences, 13(3):408-414.

Akwe, J. A. (2014): Impact of Non-Oil Tax Revenue on Economic Growth: The Nigerian Perspective. Intl Journal of Finance \& Accounting, 3(5):303-309.

Brandt, P. T. and Freeman, J. R. (2006): Advances in Bayesian Time Series Modeling and the Study of Politics: Theory, Testing, Forecasting and Policy Analysis. Political Analysis. 14(1):1-36.

Brandt, P. T. and Freeman, J. R. (2009): Modeling Macro-Political Dynamics. Political Analysis. 17(2):113-142.

Caraiani, P. (2010): Forecasting Romanian GDP using A BVAR model. Romanian Journal of Economic Forecasting. 4:76-87.

Cooray, T. M. J. A.(2008): Applied Time series Analysis and Forecasting. New Delhi: Narosa Publising House.

Offia, N. P.(2012): The Impact of Non-Oil Export on Economic Growth in Nigeria (1986-2010). BSc Thesis, Caritas University, Amorji-Nike, Enugu.

Okezie, S. O. \& Azubike, J. U.(2016): Evaluation of the Contribution of Non-Oil Revenue to Government Revenue and Economic Growth: Evidence from Nigeria. Journal of Accounting and Financial Management, 2(5):41-51.

Okwori, J. \& Sule, A.(2016): Revenue Sources and Economic Growth in Nigeria: An Appraisal. Journal of Economics and Sustainable Development, 7(8):113-123.

Omachi, A. O.(2011): Effects of Public Revenue on Economic Growth in Nigeria (1980-2008). MSc Thesis, Ahmadu Bello University, Zaria.

Oziengbe, S. A.(2015): Import Penetration, FDI Inflows and Non-Oil Export Performance in Nigeria (1981-2012): A Cointegration and Error Correction Analysis. Botswana Journal of Economics (BOJE), 13(1):40-67.

Sims, C. A. and Zha, T. (1998): Bayesian Methods for Dynamic Multivariate Models. International Economic Review. 39(4):949-968. 
Sims, C. A. and Zha, T. (1999): Error Bands for Impulse Responses. Econometrica. 67(5):113-1155.

Ude, D. K. \& Agodi, J. E.(2012): Investigation of the Impact of Non-Oil Revenue on Economic Growth in Nigeria. IJSR, 3(11):2571-2577.

\section{Appendix A}

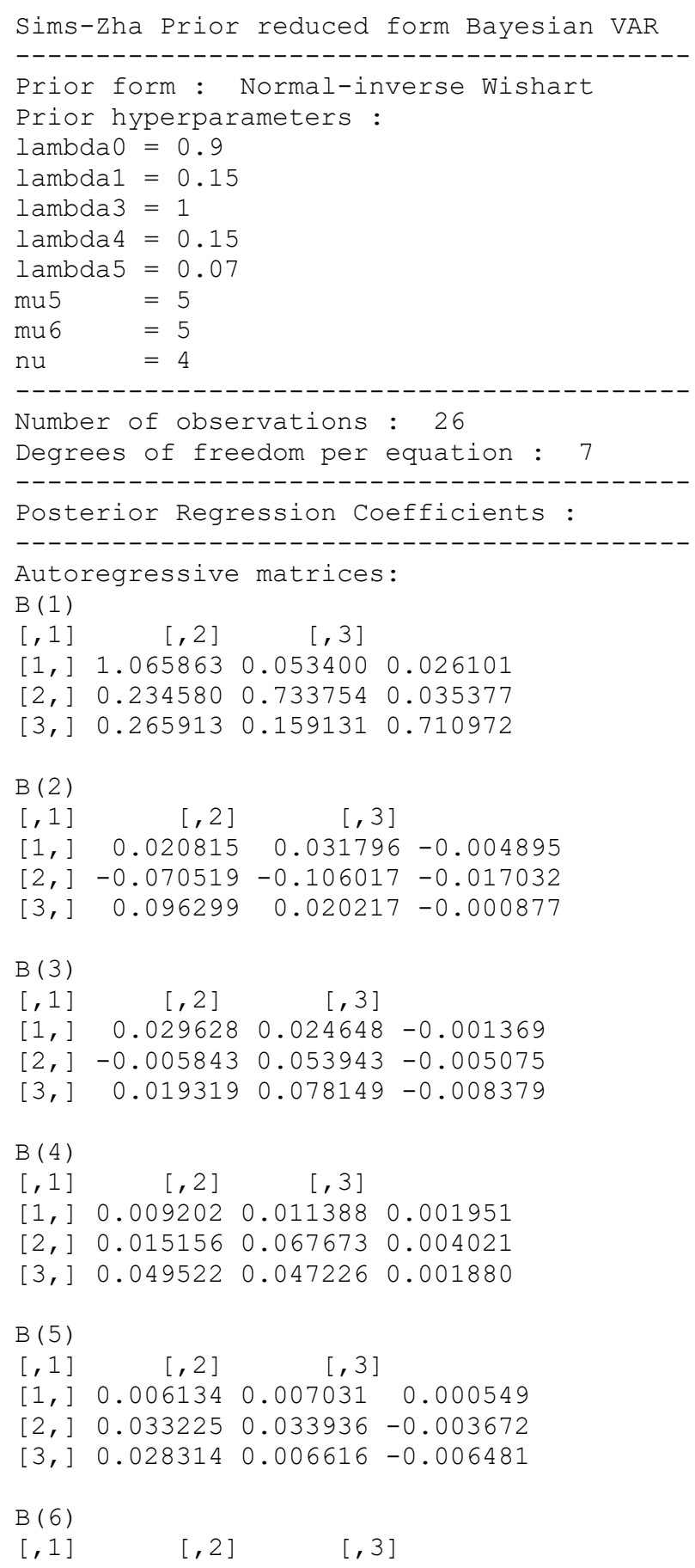




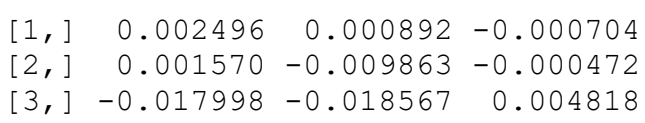

\section{Appendix B}

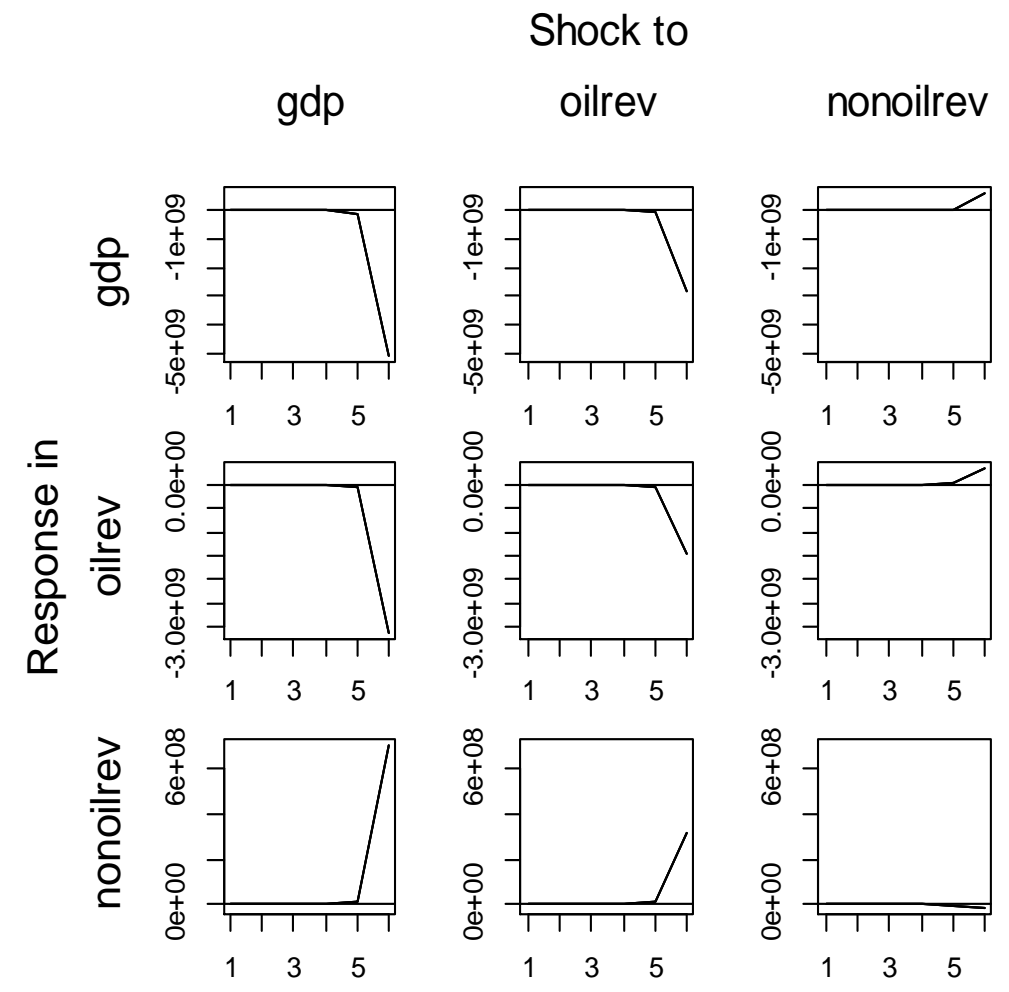

Appendix C

Decomposition of Forecast Errors for a Shock to gdp
Std. Error




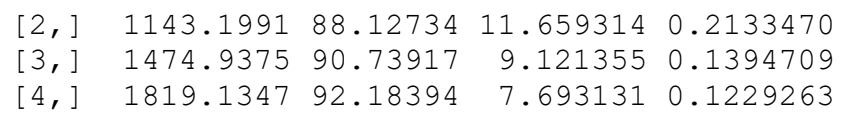

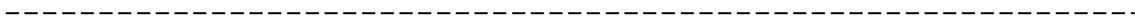

Decomposition of Forecast Errors for a Shock to oilrev

$\begin{array}{rrrrr} & \text { Std. Error } & \text { gdp } & \text { oilrev } & \text { nonoilrev } \\ {[1,]} & 406.0257 & 0.000000 & 99.93128 & 0.06871849 \\ {[2,]} & 514.4502 & 3.632023 & 96.14352 & 0.22445996 \\ {[3,]} & 568.3475 & 10.222174 & 89.44650 & 0.33132222 \\ {[4,]} & 617.2525 & 18.473032 & 81.15791 & 0.36905860\end{array}$

Decomposition of Forecast Errors for a Shock to nonoilrev

Std. Error gdp oilrev nonoilrev

$[1] \quad 163.2092 \quad 0.000000 \quad$,

$[2] \quad 206.5427 \quad 4.415172 \quad 1.581163 \quad$,

$[3] \quad 247.8532 \quad 18.995612 \quad 4.127369 \quad$,

$[4] \quad 303.8179 \quad 37.475378 \quad 7.197465 \quad$,

$>$ 